\title{
Los hijos de los conversos
}

\author{
ENRIQUE SERRANO*
}

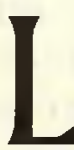

eyendo "De los judios en la historia de Colombia" de Daniel Mesa Bernal, pueden sacarse muchas, y muy impresionantes, conclusiones sobre el origen de nuestra idiosincrasia, y sobre la voluntad de acaIlarlo todo, que parece haber por debajo de la mentalidad que llevamos a cuestas. Por ejemplo, que la vida colombiana, y latinoamericana en general, carece de una historia que cuente quiénes fuimos, por qué vinimos y vivimos aquí, y qué nos ha movido a creer ya no en nuestras pobres naciones, en el sentido político y restringido, sino en lo que somos, es decir en estos muchos seres que amamos y odiamos. Y carece de esa historia por razones, a su

* Escritor colombiano. Ha publicado los libros de relatos: "La marca de España" y "En nombre de Dios".

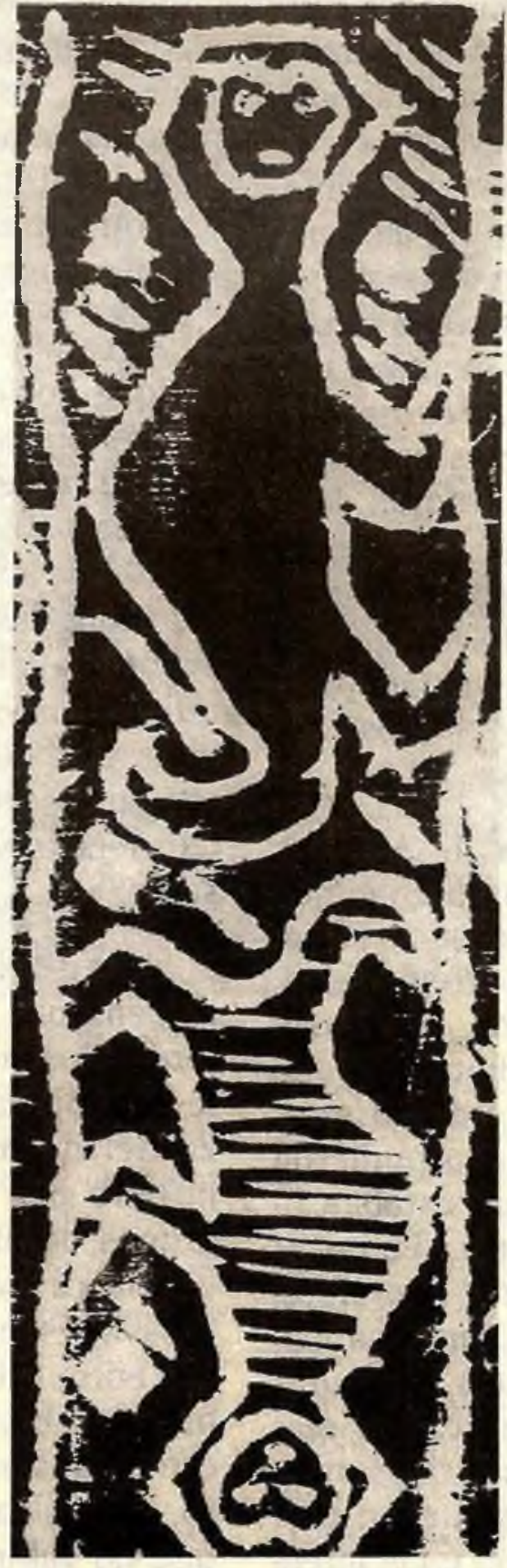

vez, históricas, es decir, elementales y profundas.

Nuestro acervo fundamental de conciencia sería el de los que vinieron, y no el de los que estaban aquí. Nuestro pensamiento y voluntad han sido movidos por fuerzas europeas, con herramientas europeas y a través de canales europeos y de este modo hemos sido, en todo punto importante, tan sólo hispanos desarraigados y despreciados, que han pagado el alto precio de la mediocridad y de la pequeñez durante cuatro siglos. Los latinoamericanos, y me refiero a una mayoría crucial, que habla español y lleva cuestas el influjo certero de la mentalidad católica, somos producto de una cultura de conversos, que fueron los que impulsaron el nacimiento y desarrollo de naciones, y los que se quedaron aquí a administrarlas y gozar de sus frutos. 
Esto es cierto incluso entre los pueblos de fuerte arraigo indígena, en donde la hispanidad actual es tan imperfecta, y en la que grupos de conversos desterrados y agrupados entre montañas distantes se habrían internado para lavar con ausencia la mancha fundamental de no haber sido cristianos durante largos siglos. Sus mezclas raciales, por fuertes que hayan sido, no habrían salido del círculo cultural de los criollos, y el resultado político y social es el de sociedades básicamente hispanas, que han arrastrado desde su misma formación una inferioridad racial y étnica que todavía no consiguen desterrar. Las huellas de esta inferioridad se hacen sentir en mil direcciones, pero se manifiestan más acusadamente en aspectos tales como la casi imposibilidad de consenso político, una marcada carencia de esprit de corps entre los miembros de las jóvenes naciones, gran indiferencia hacia la historia, débil identificación con la cultura a la que estamos aferrados, un desmesurado arribismo, y una suerte de tribalismo basado en el color de la piel y en la mayor o menor posesión de rasgos blancos y de marcas culturales europeas.

Los pueblos mestizos de América surgieron en el único mundo en el que forzosamente fue posible que surgiesen. $Y$ crecieron entre los arrepentidos, los cobardes, los vigilados, los perseguidos y los apóstatas. Entre los que renegaron de su madre y de su raza. Entre los que finalmente no pudieron volver a España, pero que estaban ligados a ella hasta la muerte. En pocas palabras, entre los malditos conversos. Nosotros, quiero decir la inmensa mayoría de nosotros, seríamos sólo unos de tantos entre ellos, nunca los más importantes, nunca los más ricos, nunca los más cultos. Otros fueron más desafortunados, y murieron en el inten- to. Incluso entre los conversos hay jerarquías y grados, y nosotros no seríamos particularmente los mejores libradós. Héroes y mártires de esa migración angustiada y vacilante, de esos cristianos nuevos sin alma, pero desmedidos, que habríamos sido durante cuatrocientos años, por lo menos, nos hemos ganado nuestra propia incomprensión y la garantía de una mentalidad conflictiva e incoherente, que sin embargo no sabe tomar otro rumbo y ser algo distinto de lo que le marca su origen. Así, los latinoamericanos resultamos ser una sociedad conservadora y tradicionalista que, no obstante, reniega con furia de su pasado y se autoexcluye como adalid del futuro.

Creemos que somos casi iguales a los que nos desprecian, y hemos crecido añorando con envidia llegar a ser lo que no podemos ser. Jamás europeos, aunque hablemos su lengua, sintamos el peso de su religión y llevemos a cuestas todas sus taras, y entre ellas, la de sentirnos inferiores a alguien, por cualquier motivo y para siempre. Jamás unos verdaderos occidentales, aunque tengamos de ellos al menos la mala conciencia, y todo lo demás que hace sufrir.

Nuestra historia es la de los no indispensables, la de los criados, los bastardos, los mestizos, producto de inconfesables licencias de sangre. La vergüenza del deshonroso nacimiento sería nuestro sino unificador. Provenimos de grupos de judaizantes y moriscos que vinieron a esconderse en América, y que todavía estarían escondiéndose, aislados entre tribulaciones y reproches que otros pueblos han podido resolver. Buscamos ansiosamente el reconocimiento, la igualdad, la desprevención de los que no valoran la cuna, ni el apellido, 
ni los abolengos. Demócratas por necesidad, ya que no por convicción, anhelamos un anonimato refrescante, al menos por un tiempo, pero también se han exacerbado en nosotros las pasiones rastreras, y por encima de todas, la de la venganza.

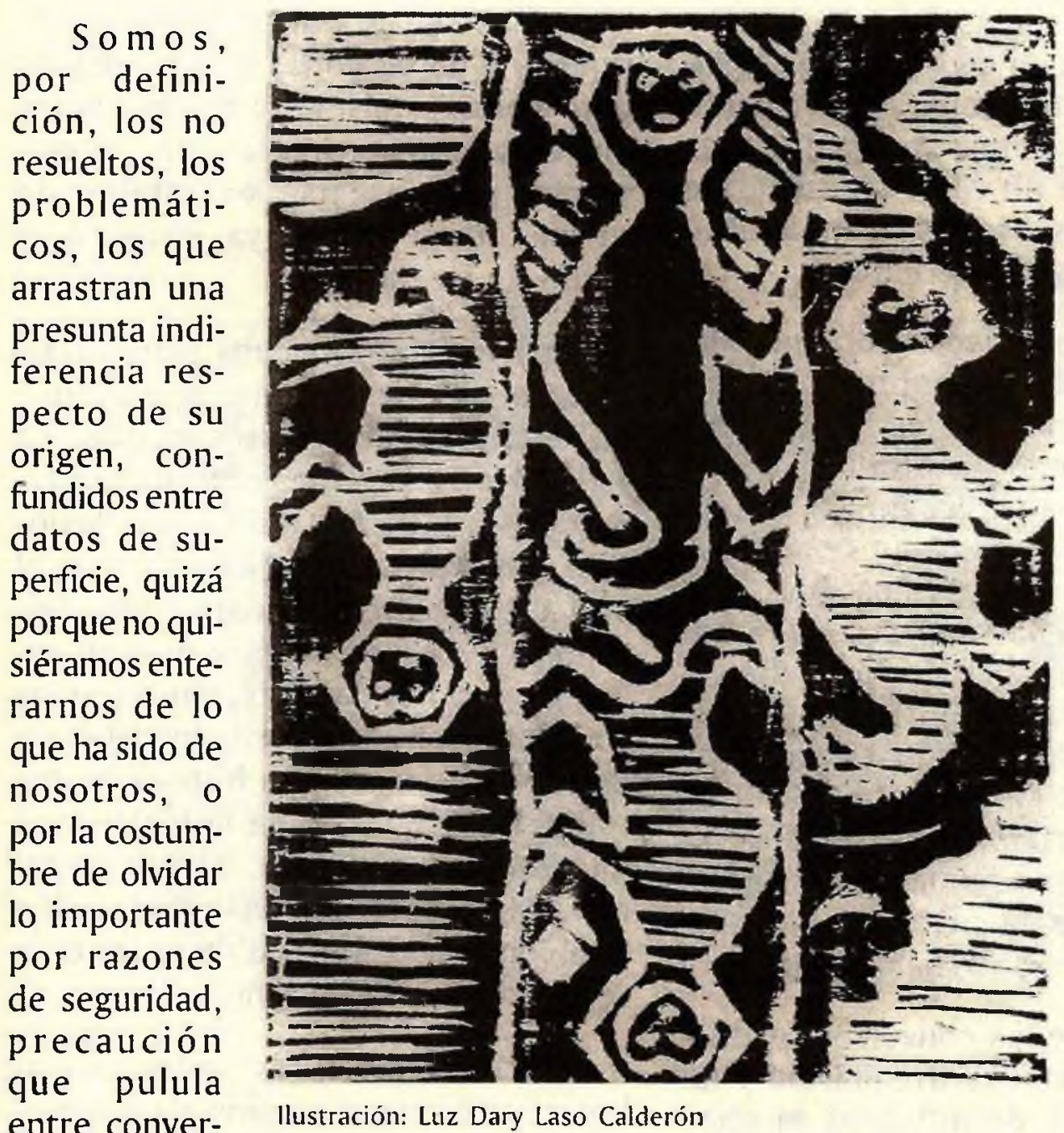

les particulares e intrascendentes, no ha sido virtuoso. Hemos pasado por mil caminos para hacer este mundo imperfecto en el que vivimos, con la incertidumbre de no saber qué somos exactamente, pero presintiendo ser precisamente, los impuros, los que no rec u e rda $n$ nada del pasado y no saben por qué. Los que están atados a una tradición que no comprenden, que no respetan, fatal en más de un sentido, y que se les ha presentado recientemente como una maldición.

Los indios de América habrían sido tan sólo, para nosotros, un accidente de la sos. Estaríamos pues, signados por la fatalidad del silencio y la violencia hacia una historia vergonzante, cargada de una iniquidad fundamental, un mal de origen, una suerte de pecado original, que habría atravesado impunemente los siglos de intolerancia religiosa, para venir a instalarse en el presente y a proliferar en el futuro.

El itinerario de este tránsito hasta el siglo XX, destinado a figurar en ana- suerte. Y así sus rostros achatados y sus vientres sin valor. Habríamos tenido a quien despreciar después de haber sufrido tanto desprecio. Nunca podremos sentirnos parte de la indiada, ni estimar en mucho sus productos. Su destino nos ha parecido una suerte de renuncia, de intolerable atraso, fuente de superioridad y de orgullo de criollos. Ellos serían las minorías que sucumben ante nuestro paso, como lo fuimos nosotros también respecto de 
los castellanos, durante los largos siglos de nuestra dolorosa gestación. El indigenismo de los últimos tiempos no resulta ser más que una mueca más, que una vulgar mala conciencia se da el lujo de proferir. No querríamos ni sabríamos ser como los indígenas, por más eufemismos que inventásemos, ni podríamos compartir con ellos más que la superficie de un territorio relativamente desconocido, y en una lengua que es la nuestra y no la de ellos, en medio de los mitos que sobre los buenos salvajes nos han llegado de Europa.

En fin, hemos dado á luz una historia plagada de exabruptos y de gritos, buscando una voz verosímil, pero siempre temiendo no producir buena impresión. Nos parecemos al inquilino escandaloso y soez que se acerca a su vecino con adornadas palabras para disculparse por las molestias que hubiera podido producir un "leve altercado" que habría promovido la noche anterior, interrumpiendo el sueño de todo el mundo. Molestos con nosotros mismos, trataríamos inútilmente de corregir del error fundamental de haber sido, precisamente, algo muy distinto de lo que esperábamos ser.

Los hijos de los conversos tendríamos una expectativa irrealizable y fanática respecto de nosotros mismos que, en tanto que frustrada, nos sirve para hacer uso del incansable reproche, un arma eterna de los seres aislados y resentidos, y que produce miedo y parálisis, los ingredientes secretos de una cómoda inconstancia, que seduce a nuestras mujeres y basta para nuestros hijos. Esta conciencia parroquial, tan católica, ha sido nuestra salvación y nuestro obstáculo durante más años de los debidos y explicaría una parte de las dificultades digamos metodológicas, por las que atravesamos hoy para insertarnos en un mundo de claro ascendiente anglosajón.

Indeseables en el fondo, sabemos que merecemos algún lugar en el mundo, aunque hubiésemos renunciado a la posibilidad de poblar la casa de la riqueza o de la gloria. El converso es duro consigo mismo, y muchas veces innecesariamente implacable, porque emplea para juzgarse los criterios de su amo, de su opresor, ya idealizado y salido de su estampa.

Esta vendría a ser una gran revelación, la cara del misterio que incluso no declaramos de nosotros mismos. La estupidez reinante nos ha protegido, hasta ahora, de $\tan$ molestas reflexiones, y durante larguísimo tiempo el enclaustramiento juridicista e ideologizante que hoy se disfraza de comunidad política nos ha protegido de actuar en consecuencia respecto del deber de autocomprendernos. La historia no narrada, la encubierta, de la mentalidad que llevamos a cuestas, ha sido generalizada y exagerada, con lo cual ha sido también mal comprendida, y las consecuencias se hacen sentir.

Muchas teorías, casi todas sin elaborar, yacen en el camino de tan mediocre destino, sin que hayamos podido estimar alguna (o algunas), para responder a nuestras más atribuladas limitaciones y cacareadas falacias. Pero, parece que está llegando la hora de decirnos, sin rodeos y de una vez por todas, qué identidad hemos tenido y cuál es la que verosímilmente podemos tener como baluarte para hacer el tejido del futuro, si es que acaso eso puede contribuir a alcanzar algo importante en los siglos por venir. 